\title{
Expanding translation studies: a (bio)semiotic approach
}

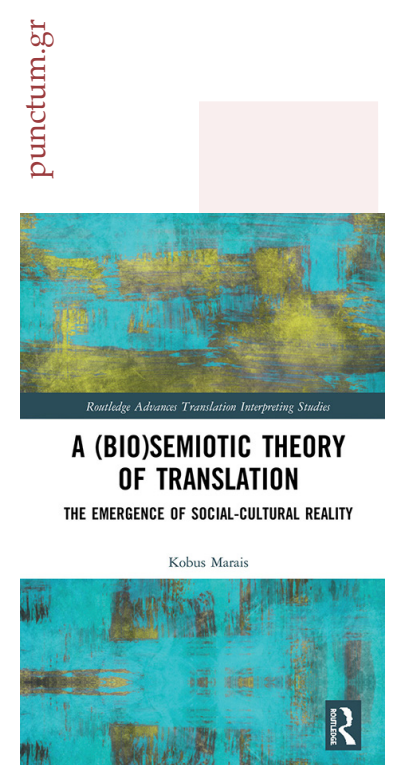

ARTICLE INFO:

\begin{tabular}{l}
\hline Volume: 07 \\
\hline Issue: 01 \\
\hline Summer 2021 \\
\hline ISSN: 2459-2943 \\
\hline DOI: 10.18680/hss.2021.0013 \\
\hline Pages: 181-191 \\
\hline By: Margherita Zanoletti \\
\hline Lic.: CC BY-NC-ND 4.0
\end{tabular}

BY: Margherita Zanoletti

Marais, Kobus.

\section{A (Bio)Semiotic Theory of Translation:} The Emergence of Social- Cultural Reality.

London: Routledge, 2019, 208 pp. $£ 37.00$ (pbk, ISBN 978-0367-584-139).

$\mathrm{T}$ his is a first-person book, in which the author's ' $\mathrm{I}$ ' author guides readers, step by step, along a multidisciplinary journey that merges semiotics, social semiotics, translation studies, cultural studies, and development studies. A (Bio)Semiotic Theory of Translation provides a narrative, ground-breaking discussion on the very concept of translation, in dialogue with an impressive variety of data and ideas. It is a radical and ambitious project aimed at shaking the foundations of translation studies.

The author's aim is declared in the opening pages and then repeatedly, almost rhythmically recalled to readers through the chapters. Kobus Marais' leading concern is that translation studies, which should deal with all process phenomena, have mostly limited itself to the notion of interlinguistic translation and urgently needs to reconsider its roots. As Marais explains, some "trans," "hyper," and "inter" terminology has been employed to expand the notion of translation beyond the interlingual paradigm. However, such terminology has broadened the context in which interlingual translation is studied more than its conceptualization. Definitions of translation restricted to verbal language have become limited and inadequate for a rapidly evolving scenario. The urgency of this reconsideration is in everyone's eyes. Modern communication has turned increasingly hybrid and multimedial (Susam-Saraeva 2016), while "pure" interlingual translation is set to decline. More and more often, under digital technology and the ability to construct meaning in multiple 
forms, current culture experiences the simultaneous release of movies with videogames, apps, gadgets, and tools, etc. Even services (and not just products) are semioticized as multi-channel. Put simply, communication is becoming more and more complex. However, the ever-increasing complexity of communication is not the only reason why Marais considers the exclusive focus on language a bias. Since time began, humans do not communicate with words only but with various semiotic tools, and a linguistic-only conceptualization of translation studies is overly narrow. Besides, human language is not the only medium of communication worthy of interest: it is about time to rethink our relationship with non-human organisms and account for a whole range of biosemiotic interactions as providing the context for specifically human communication. Marais wishes for a breakthrough to occur. Translation studies scholars should adopt a broader theoretical framework and shift their interest from translations and translators to translationality. The founding stone for this new framework should be Charles Peirce's view of translation. Peirce's semiotic theory can lay the foundation of a renewed perspective in translation studies.

Roughly speaking, A (Bio)Semiotic Theory of Translation is structured in two parts: a pars destruens and a pars construens. Although destruens elements and construens elements are often integrated (the first part of the book contains previews of Marais' theorization illustrated in the second part, and vice versa, the critique contained in the first part is recalled and reinforced in the second part), the destruens component sounds particularly strong. To be fair, such an engaging discussion would have deserved more room than 190 pages in all. But overall, Marais' intent is achieved. The book is effectively structured and written. Each chapter starts with an overview of the steps taken in the following pages, reminding readers how particular topics fit the whole project. Densely and solidly, the author proves himself capable of making his point, fuelling the discussion, and laying the groundwork for further reflection.

In the pars destruens of the book (Chapters 2 and 3), Marais provides a guided overview of crucial past contributions to the conceptualization of translation, intent on probing and exposing their linguicentric and anthropocentric bias. Marais claims that since becoming a discipline, translation studies in the Western world has been conceptualized almost exclusively in terms of language, literature, and culture, basing itself mainly on Roman Jakobson's renowned tripartition featuring intralingual, interlingual ('translation proper'), and intersemiotic translation (Jakobson 1959[2004]). Although Jakobson did consider translation processes between nonverbal and verbal sign systems, observes Marais, he turned Peirce's broad notion of semiotics as a theory of all signs into a conceptualization of the semiotics of verbal language. Consequently, following generations of translation studies, scholars grew up with the notion of translation as interlingual translation, and the bias perseveres.

Several attempts have thematized the relationship between semiotics and translation, but Marais contends that the implications are not fully explored. Examples 
abound. Among the authors discussed, Eugene Nida (1964) considered translation, in whichever form, to be a matter of meaning. Still, his understanding of semiotics, argues Marais, was limited to human communication and linguistic semantics. Similarly, James Holmes (1972[2004]) too had interlingual translation in mind when conceptualizing the field. The efforts by Gideon Toury (1995), George Steiner (1998), Mona Baker (2006), Maria Tymoczko (2007), and Ubaldo Stecconi (1994, 2004, 2007, 2010) are seminal but incomplete. As recounted by Marais, Toury prefigured the subsequent arrival of translation sociology; Steiner extends translation far beyond the verbal medium and takes it as a process that explains all meaning-making, while Baker discusses translation, communication, and conflict. Marais acknowledges Tymoczko as "one of a very few scholars who engage the topic [of conceptualizing translation studies] philosophically," including practices and styles from all over the world and empowering translators to become agents. Stecconi is "the key figure, after Jakobson, to consider a semiotic theory of translation," distinguishing between semiosis as a larger category and translation as an instance of semiosis. Yet, these different authors have in common that they keep referring to a theory of language. In their work, nearly all references are to languages and texts, limiting their analysis primarily to interlingual translation.

In the same period, Christiane Nord's functionalist approach, André Lefevere's notion of rewriting, and Susan Bassnett's cultural turn expanded translation studies to include the biosemiotic, semiotic, and cultural aspects of linguistic communication, enabling the conceptualization of translation as more than linguistic interaction. But semiotic thinking on translation has increased even more significantly in the last fifteen years. For instance, Sergey Tyulenev (2012) defines translation in systemic rather than linguistic terms. Yves Gambier and Luc Van Doorslaer (2016) emphasize that within translation studies, theoretical issues are often ignored in favor of pragmatic, marketable solutions and assume that a deep-going view of translation entails a metaphoric use of the word translation. Douglas Robinson (2015) attempts a dialogue between East and West and stretches the notion of translation beyond the rational, arguing that translation is based on empathy. Karen Littau (2016) wants to consider materiality in translation, questioning the focus on ideas to the exclusion of media. However, all these authors only use examples of interlinguistic translation, and their dominant notion of translation continues to be interlingual. In effect, their perspective expands the notion of interlingual translation but not the notion of translation.

In the following chapter, Marais destructor turns his attention to semiotics and considers authors based on Peircean semiotics. In this case, as with translation studies scholars, logocentrism and anthropocentrism are radically critiqued. Although among semioticians, concedes Marais, the conceptualization of translation is broader than among translation researchers, three biases are still evident: first, they tend to see sources and targets as stable rather than dynamic elements; second, they often 
indulge in examples of interlinguistic translation; and third, they rely on concepts such as equivalence, source text and target text, which limit their perspective.

According to Dinda Gorlée (1994), for example (whom Marais recognizes as the first author attempting to align the notion of translation with Peircean semiotics), the entire set of semiotic phenomena is greater than the set of linguistic phenomena. Both humans and non-humans make and take meaning that is not linguistic. In a similar vein, in Kant and the Platypus (1997), Umberto Eco explores how new information from the natural world is "semioticized" into cognitive systems of meaning. This morphological process, stresses Eco, is the most basic form of translation occurring in all living organisms. Amongst the authors reviewed, Susan Petrilli is considered by Marais as a "pioneer" of intersemiotic translation. Petrilli $(2003,2015)$ maintains that semiotics and translation study the same process from different perspectives and that "to translate is to interpret," to create relationships. Moreover, according to her, we must overcome anthropocentrism and logocentrism, as "verbal signs constitute only a tiny sector of the signs on our planet." She emphasizes that signs are always in translation, unstable, in the process of being translated into further signs. Petrilli's contribution is labeled by Marais as paramount, although to this date, he laments, her work has been considered far too limited by translation studies scholars.

Marais considers Peeter Torop as another forerunner on thinking on intersemiotic translation. A follower of Jurij Lotman, Torop has strived to show how culture emerges out of translational activities and to expand the notion of translation to include all aspects of culture (Total'nyj perevod [Total translation], 1995). To him, translation is relational and connected with thought, while culture results from manifold translation processes. He underlines that even monomedial texts entail more semiotic dimensions than merely the linguistic (e.g., font types, colors, etc.) and devotes much of his study to intermediality. Another influential author discussed by Marais is Evangelos Kourdis. Kourdis emphasizes that, in modern communication, registers have become both pictorial and linguistic, making intersemiosis the norm and the distinction between words and images difficult. Finally, Joao Queiroz raises the point of biosemiotics, proposing that translation is not a binary process between a source and a target, but rather, along Peirce's lines, a triadic process involving representamen, object, and interpretant. With Queiroz, furthermore, the themes of evolution and non-human communication are added to the agenda.

All this is grist for Marais' mill. One after the other, authors are reviewed and criticized when not dismantled. Their reasoning always seems to lack one central point: interlingual translation is not the paradigm. Marais claims that Gorlée does not account for non-human semiosis and focuses on examples of interlingual translation. She devotes ample time to the problem of equivalence, talks about original and translation, and concentrates on the translation of symbols, neglecting iconic and indexical 
signs. Similarly, according to Marais, the most significant limitation of Eco's work is restricting the notion of translation to interlingual translation, which explains why Eco considers translation a subcategory of the broader process of interpretation. When citing Jakobson, Eco refers to "translation proper." To him, therefore, "interlingual translation" appears to be the proper meaning of the term.

Debatable, according to Marais, is also Petrilli's terminological distinction between intersemiotic and endosemiotic translation because all translation must be viewed as occurring between semiotic systems anyway. Likewise, Marais criticizes Torop's insistence on "semiotic fidelity," on the relation source/target, which tends to suggest a static view of translational processes, and on his adoption of the linguicentric word "text" to refer to cultural artifacts. And Kourdis and Queiroz are not spared faults: the first lacks a biosemiotic view, while the second focuses on aesthetic data only, ignoring social and cultural data.

In the last part of his critical overview, Marais discusses three big names of multimodality thinking: Gunther Kress, Lars Elleström, and Göran Sonesson. The shared idea is that meaning rarely occurs in one mode of communication but is primarily multimodal. Therefore the complexity of communication requires a complex theory of translation. Also, their research line clarifies that the meaning-making process starts with perception, not with the formation of ideas. According to Elleström, for instance, "all kinds of sign systems ... must be seen as part of a vast field including the material, sensorial, spatiotemporal and semiotic aspects".

In Chapters 4-6, readers are plunged into the pars construens of Marais' argumentation. Here, by exploring the relationship between translation and semiosis, the author illustrates his conceptualization of translation, opening the discussion to future developments. His purpose is to address the linguistic bias in the field, shifting the debate to the semiotic level and the multitude of 'inter' and 'trans' phenomena in which language does not play a role at all and traditional translation studies are not able to tackle. From this perspective, the author attempts to integrate previous works and authors, including those mentioned in his pars destruens, into a constructive theory.

The starting point is Peirce's notion of translation, which Marais presents and discusses as the engine and basis of his conceptualization in the fourth chapter. As is well-known, according to Peirce, all thought is in signs: we think by relating signs to one another. A sign consists of and is a process of connecting three semiotic functions: representamen, object, and interpretant. Moreover, even those least acquainted with Peircean semiotics are aware of his distinction among three categories of signs: icons, indexes, and symbols. Language, we recall, is symbolic, as it has a conventional or arbitrary relation with the object. At the same time, icons relate to the object by resemblance, and symbols are connected to the object by a nexus of causality. 
In his definition of translation, Peirce does not mention languages, as Jakobson unfortunately does. In Peirce's theorization, semiosis is a never-ending process, and translation is a technical term that refers to the semiotic process in all its guises. According to the semiotician, translation generates meaning by relating two things out of the universe's chaos. The outcome of the process is interpretation, namely, the creation of interpretants. From this perspective, translation entails all types of meaning-making and meaning-taking actions: it pervades not merely language and not only all human culture and society, but the whole cosmos.

The all-pervasiveness of translation is tackled in the last part of the chapter, where Marais refers to biosemiotics as a crucial area of study that can contribute to expanding translation studies. Biosemioticians agree that human beings have the most developed semiotic abilities and that language is the most complex and developed semiotic code. Yet, language is only an aspect of translationality (Dizdar 2009), and humans are not the only organisms with semiotic skills. In fact, biosemiotics engages in a discussion within theoretical biology about overcoming the assumption that meaning-making and meaning-taking are only human activities. From a biosemiotic perspective, intentionality and communication are ubiquitous in living organisms.

Even within the pars construens, Marais does not lose a chance to unleash his critique and repeat his mantra: the linguicentric bias caused by Jakobson's addition of the term "lingual" to his definition of translation has limited and weakened the field of study. An evident symptom is that "traditional" translation studies have studied only or mainly symbols (in primis words), while iconic and indexical signs have received inadequate attention. Moreover, non-human semiosis has remained undertheorized by translation studies scholars. The lack of a general theory of meaning-making and meaning-taking constitutes a severe flaw, echoes Marais, and this situation needs to be corrected. The use of language must be embedded in a wide-ranging theory of signs such as Peircean semiotics, able to explain what is common to all types of signs.

In Chapter 5, Marais further expands his constructio. The author begins from one straightforward premise: at stake are not instability and indeterminacy, but instead stability and determinacy (Fuchs 2009). Traditionally, the source text has been regarded as something static, having stable, formalized meaning. According to Marais' line of thinking, in contrast, the problem of translation is not turning one (stable) instance of meaning into another (stable) instance of meaning, but rather the process of change that triggers meaning-making and meaning-taking.

Marais' thought has also been inspired by Floyd Merrell's work on semiotic processes. Two main points of Merrell's theory are emphasized as particularly significant. First, the reality is motion and interplay; therefore, semiotic processes are not linear but require a complexity perspective. Merrell calls translation the negentropic process of change that 
turns signs into more endangered signs, allowing meaning to emerge from entropic chaos. Second, semiosis is not abstract but concrete. Usually, translation studies only focus on conscious, cognitive, and conceptual things: humans tend to lingualize or symbolize all signs. On the contrary, Merrell coins the terms "bodymind" and "bodymindsign" to indicate the unity between phenomena that we tend to conceive as separate. From this perspective, Marais stresses that language is not the only mode of meaning-making: iconicity and indexicality provide information that language cannot convey. We need to find ways of understanding meanings that we cannot express in words.

Besides Merrell, another primary source of Marais' inspiration is complexity thinking. According to the author, a complexity approach to translation aims to explain the emergence of semiotic organization, habit, trajectory, and pattern that arise through the translative process. Complexity thinking assumes chaos or nothingness as the origin of everything. Similarly, as Marais argues, culture emerges through translation as negentropic work: the chaotic stream is constrained to a particular form because of the causative effect of semiotic possibilities that have not been realized.

In the second part of the Chapter, drawing on the premises announced earlier and, across and above all, Peircean semiotics, Marais constructor unveils his conceptualization of translation. He provides definitions for translation and translation studies and proposes to replace Jakobson's categories.

Marais' conceptualization of translation derives mainly from Peirce. Marais defines translation as negentropic semiotic work, in which any one or more of the components or relationships between components of a sign system or the relationship between the sign and its environment are transformed. This processual work is never-ending and historically irreversible. In Peirce's view, semiosis is the continuous creation of relations between triads of representamen, object, and interpretant; all signs are related to other signs; they are relationships. Translation thus entails any movement or change in either space or time to existing relationships, the creation of new relationships, or any shift in the space-time context in which the translative process occurs. From this perspective, Marais proposes to replace the terms "source text" and "target text" with the terms "incipient sign system" and "subsequent sign system" to emphasize the timebased, intersemiotic and intersystemic nature of all translative processes. In this context, it is now clear that the focus of translation studies should not be the final product but rather the process. The real questions ought to be: how does the translation process unfold? By what is it constrained? In Marais' view, equivalence is irrelevant, whereas the main point is to investigate the constraints under which processes become determinate. Everything could have a translational aspect to study.

In line with this view, the categories of translation put forward by Marais are categories of process, not types of things. He suggests the categories intra-systemic, 
inter-systemic, and extra-systemic, irrespective of what those systems are. This theoretical framework renders Jakobson's tripartite schema (intralingual/ interlingual/intersemiotic) obsolete since all translation happens between semiotic systems. Another categorization distinguishes among translation processes initiated by a change to the representamen, the object, and the interpretant, respectively. As the process unfolds, we should add, neither of the three elements remains unaffected.

Representamen translation entails changes to the materiality of the representamen, that is, the material nature of the sign-vehicle. This category is currently studied in interlingual translation studies, adaptation studies, multimodality studies, and multimedia studies. Marais specifies that we can have five subcategories of representamen translation: visual, aural, tactile, olfactory, gustatory. In addition, the representamen can be purely mental (a thought, an idea, a dream).

Among the book's critical insights is the remark that object translation is the weakest of the three tendencies in translation. However, it offers conceptual tools for gaining insight into the emergence of society/culture. This type of translation entails changes to the object, i.e., the other to which the representamen stands in a relationship. Any change in the object will also affect the interpretant. For example, a dog can be a companion in one culture and food in another; or we can translate a medical textbook into a general public book. Concerning object translation, Marais makes a digression on John Deely, who explores the concept of relationality as the basis for the construction of meaning, and whose work affects Marais' theorization. According to Deely, meaning relates three elements, and knowledge is based on complex relationships. All things exist in the world as interdependent, and we construct and co-construct through negotiation. Translation is the process by which such relationships are established.

Interpretant translation implies that the interpretant is changed, and signs become other than what they are. For instance, reading a novel for the second time would be such a case. In this type of translation, an interpretant is taken as a representamen and translated through the semiotic process into a more or less developed interpretant.

In Chapter 6, Marais takes the final step of his pars construens and applies his conceptualization of translation to the emergence of socio-cultural phenomena. To start with, the author explores the implications of William Deacon's book Incomplete Nature (2013), whose central idea is that ententional process-phenomena emerge through a process of imposing constraints on possibilities. Deacon's thinking is particularly significant, as it contends idealism in cultural studies, stressing that representations and ideas are not immaterial but rather made of physics and chemistry. The term "ententional" is a neologism that applies to the class of objects and phenomena that refer or relate to something not present. All living organisms are ententional, namely, driven by future outcomes. By incorporating Deacon's theory into his theory, Marais' 
definition of translation as negentropic work becomes "negentropic imposition of constraints on semiotic processes." According to this definition, societies and cultures emerge through semiotic work that counters entropy (translation).

Deacon coins the term "ententional" to refer to all teleodynamic processes or systems: in other words, the processes driven by an as-yet-unrealized set goal. Following Deacon, Marais argues that all translation is teleodynamic, that is, aimed at the imposition of constraints on semiotic processes. Once an energetic or informational asymmetry develops because of constraints, it tends to cause further constraints, enlarging the asymmetry. Such asymmetry becomes an attractor, namely, a tendency with a causal effect.

In the last stage of his pars construens, Marais suggests a research paradigm based on object translation, focused on indexical signs that imply a causal connection between representamen and object; this paradigm allows the study of sociocultural forms as indexes of the processes that formed them. This conclusive argument develops in four main steps.

As a first step, Marais emphasizes that humans do not exist merely in the world of ideas but rather in a mixed weave of ideas and physics, matter, and dreams. The notion of meaning must therefore be non-idealist and pragmatic. He mentions how Bruno Latour's and Eco's work pointed at object translation as relevant for the sociology of knowledge. In particular, Latour argues that knowledge is thoroughly social and that non-human and even non-living things are intertwined. Semiosis is the interface between nature and culture: the "social" that we can observe corresponds to the traces of the processes by which it formed. For Latour, translation (world-making) is the process by which data or ideas are turned into semiotic phenomena.

As a second step, Marais maintains that the Peircean notion of degenerate sign, namely, indexical signs in which the relationship between representamen and object is not constructed conventionally but is regulated by cause and effect or proximity (for example, the physical symptoms of an illness), provides scholars of sociocultural emergence with a conceptual tool to study non-linguistic and pre-linguistic meaning-making. In this way, it contributes to understanding how socio-cultural forms emerge. Much of culture and society happens at a pre- or non-verbal level, and studying indexes would give us access to the preverbal and practical dimensions.

As a third step, Marais expands his reflection on the relevance of indexicality to understanding socio-cultural emergence. He observes that an index entails a representamen that is "really affected" by its object, pointing to meaning-making in reality. From this perspective, culture can be interpreted as an indexical sign of the process of its emergence. Realizing that there are also indexical signs, signs that presuppose a material context and causal relationships, implies recognizing that the Other, the context, the environment also play an essential role in constructing meaning. Translation 
theory should make room for all types of meaning-making, and the study of indexes is vital to realize that meaning is co-constructed under the constraints of reality.

Marais aims to suggest a meta-theory of translation able to explain any particular approach to translation, whether narrowly linguistic or broadly sociological. As a fourth and final step, Marais leaves readers in a provisional, almost provocative way. Admittedly, a few aspects relevant to the theme and scope of this book are left unexamined. However, the author poses five questions that foster and anticipate further studies. His ambition, it turns out, is not only to sow a novel theorization but also to lay the groundwork for future growth.

In the concluding chapter, aligning himself with a few scholars who are working towards a unified theory of matter and mind, Marais strongly advocates that "we from the humanities" are liberated from individualism and realize that we are co-constructed by innumerable Others: "people, living organisms, energy, matter, and laws of the universe."

So Marais ends as he began. Translation, he concludes, must be thought of not as a speech act but rather as a condition underlying communication as a whole. He predicts that translation studies are likely to become increasingly irrelevant in a world moving toward multimedial communication and away from anthropocentric views. Only a (bio)semiotic translation theory makes it possible to conceptualize the translational dimension of culture, society, and living organisms. Is this perspective too radical, too revolutionary? Time will tell whether Marais' ambition has gone too far or may push ahead further as new interpretants unfold for such a robust translation theory.

\section{References}

Baker, Mona 2006. Translation and conflict: A narrative account. New York: Routledge.

Dizdar, Dilek 2009. Translational transitions: 'Translation proper' and translation studies in the humanities. Translation Studies 2 (1): 89-102.

Deacon, Terrence William 2013. Incomplete nature: How mind emerged from matter. New York: WW Norman \& Company.

Eco, Umberto 1997. Kant and the platypus: Essays on language and cognition. London: Harcourt Inc.

Fuchs, Martin 2009. Reaching out; or, Nobody exists in one context only: Society as translation. Translation Studies 2 (1): 21-40.

Jakobson, Roman 1959[2004]. On linguistic aspects of translation. In: L. Venuti (ed.) The translation studies reader. 2nd ed. London: Routledge, 138-143.

Gambier, Yves \& Van Doorslaer, Luc 2016. Disciplinary dialogues with translation studies: The background chapter. In: Y. Gambier and L. Van Doorslaer (eds.) Border crossings: Translation studies and other disciplines. Amsterdam: John Benjamins, 1-22. 
Gorlée, Dinda 1994. Semiotics and the problem of translation: With special reference to the semiotics of Charles S. Peirce. Amsterdam: Rodopi.

Holmes, James 1972 [2004]. The name and nature of translation studies. In: L. Venuti (ed.) The translation studies reader. 2nd ed. New York: Routledge, 180-192.

Littau, Karen 2016. Translation studies forum: Translation and the materialities of communication. Translation Studies 9 (1): 82-113.

Nida, Eugene 1964. Toward a science of translating: With special reference to principles and procedures involved in Bible translating. Leiden: Brill.

Petrilli, Susan 2003. The intersemiotic character of translation. In: S. Petrilli (ed.) Translation translation. Amsterdam: Rodopi, 41-54.

Petrilli, Susan 2015. Translation of semiotics into translation theory, and vice versa. Punctum 1 (2): 96-117.

Robinson, Douglas 2015. The Dao of translation: An east-west dialogue. London: Routledge.

Stecconi, Ubaldo 1994. Peirce's semiotics for translation. Koine 4: 161-180.

Stecconi, Ubaldo 2004. Interpretive semiotics and translation theory: The semiotic conditions to translation. Semiotica 150 (1): 471-489.

Stecconi, Ubaldo 2007. Five reasons why semiotics is good for translation studies. In: Y. Gambier, M. Shlesinger and R. Stolze (eds.) Doubts and directions in translation studies. Amsterdam: John Benjamins, 15-26.

Stecconi, Ubaldo 2010. What happens if we think that translating is a wave? Translation Studies 3 (1): 47-60.

Steiner, George 1998. After Babel: Aspects of language and translation. 3rd ed. Oxford: Oxford University Press.

Susam-Saraeva, Şebnem 2016. In search of an "international" translation studies: Tracing terceme and tercüme in the blogosphere. Translation Studies 10 (1): 1-18.

Torop, Peeter 1995. Total'nyj perevod. Tartu: Izd. Tartuskogo universiteta.

Toury, Gideon 1995. Descriptive translation studies - and beyond. Amsterdam: John Benjamins. Tymoczko, Maria 2007. Enlarging translation, empowering translators. Manchester: St Jerome.

Tyulenev, Sergej 2012. Applying Luhmann to translation studies: Translation in society. London: Routledge.

\section{AUTHOR}

Margherita Zanoletti holds a Ph.D. in Translation Studies from the University of Sydney. As a researcher in translation theory and practice, she focuses on word and image and intercultural studies. 